\title{
Cardiac cachexia: hic et nunc
}

\author{
Goran Loncar ${ }^{1,2}$, Jochen Springer ${ }^{3}$, Markus Anker ${ }^{4}$, Wolfram Doehner ${ }^{5}$ \& Mitja Lainscak ${ }^{6,7 *}$ \\ ${ }^{1}$ Department of Cardiology, Clinical Hospital Zvezdara, Belgrade, Serbia; ${ }^{2}$ School of Medicine, University of Belgrade, Belgrade, Serbia; ${ }^{3}$ Innovative Clinical Trials, Department \\ of Cardiology and Pneumology, University Medical Center Göttingen (UMG), Göttingen, Germany; ${ }^{4}$ Department of Cardiology, Charité - Universitätsmedizin, Berlin, \\ Germany; ${ }^{5}$ Center for Stroke Research Berlin, Charité Universitätsmedizin, Berlin, Germany; ${ }^{6}$ Department of Cardiology and Department of Research and Education, General \\ Hospital Celje, Celje, Slovenia; ${ }^{7}$ Faculty of Medicine, University of Ljubljana, Ljubljana, Slovenia
}

\begin{abstract}
Cardiac cachexia (CC) is the clinical entity at the end of the chronic natural course of heart failure (HF). Despite the efforts, even the most recent definition of cardiac cachexia has been challenged, more precisely, the addition of new criteria on top of obligatory weight loss. The pathophysiology of CC is complex and multifactorial. A better understanding of pathophysiological pathways in body wasting will contribute to establish potentially novel treatment strategies. The complex biochemical network related with CC and HF pathophysiology underlines that a single biomarker cannot reflect all of the features of the disease. Biomarkers that could pick up the changes in body composition before they convey into clinical manifestations of CC would be of great importance. The development of preventive and therapeutic strategies against cachexia, sarcopenia, and wasting disorders is perceived as an urgent need by healthcare professionals. The treatment of body wasting remains an unresolved challenge to this day. As CC is a multifactorial disorder, it is unlikely that any single agent will be completely effective in treating this condition. Among all investigated therapeutic strategies, aerobic exercise training in HF patients is the most proved to counteract skeletal muscle wasting and is recommended by treatment guidelines for HF.
\end{abstract}

Keywords Cachexia; Heart failure; Prevalence; Diagnosis; Treatment

Received: 21 January 2016; Accepted: 18 March 2016

*Correspondence to: Mitja Lainscak, Department of Cardiology, General Hospital Celje, Oblakova 5, SI-3000 Celje, Slovenia: Fax: +386 342336 66, Email: mitja.lainscak@guest.arnes.si

\section{Epidemiological aspects of cardiac cachexia}

Through the prevalence of chronic disease, lack of specific therapies, or non-implementation of existing and evidencebased management, cachexia evolved to a public health issue. ${ }^{1}$ Most of the epidemiological figures are based on different cachexia definitions and derived from heterogeneous populations. ${ }^{2}$ One would hope this would change with a consensus cachexia definition published in $2008 .^{3}$ However, literature speaks for itself as we are still in need of quality and quantity on this topic. ${ }^{4}$ For heart failure (HF), as for other chronic diseases, only few studies were published, and they remain heterogenous in cachexia definition. The recent study in HF again used the old definition, namely, unintentional non-edematous weight loss of $>5 \%$ over at least 6 months. By applying this definition, cachexia was found in 19/238 (10\%) HF patients. ${ }^{5}$ In fact, a new definition was tested in a single HF study. ${ }^{6}$ In 137 patients, the obligatory criterion of weight loss was met by 42 (31\%), but when additional three criteria were requested, significantly fewer patients met the cachexia definition [30 (22\%) patients, $P=0.0006$ ]. Interestingly, no difference in survival was seen between those two patient groups. The authors therefore challenged the added value of new cachexia definition, more precisely, the addition of criteria on top of obligatory weight loss.

Nonetheless, it needs to be acknowledged that cachexia is representing a major burden for patients and the healthcare system. In the 1 year analysis of the USA Nationwide Inpatient Sample, cachexia as a primary or secondary diagnosis was reported for 32131 (0.41\%) of all admissions. ${ }^{7}$ Cachexia patients were older, had longer length of stay ( 6 vs. 3 days), and required an average of $\$ 4641$ more per hospital stay. HF was recorded for $19 \%$ of cachexia admissions and was the third most common chronic comorbidity (after malignancy, 34\%, and chronic obstructive pulmonary disease, $29 \%$ ). Based on burden in terms of costs and outcome, well-conducted cross-sectional or longitudinal epidemiological studies are urgently needed. An important source of 
information should be the Studies Investigating Comorbidities Aggravating Heart Failure that has included HF patients, diabetics, and healthy controls. ${ }^{8}$ After an extensive baseline assessment that allows for cachexia diagnosis, they were seen at regular intervals and followed-up for mortality. First reports from this study include muscle wasting aspect, which was frequent and associated with reduced physical performance. ${ }^{9}$ Along with cachexia definition, health professionals' attitudes across the chronic disease need to be changed. Screening for nutritional aspects, weight loss, and correlates in terms of physical performance and quality of life should be part of routine assessment ${ }^{10}$ as many of abnormalities may be managed in an easy way.

\section{Advances in pathophysiology of cardiac cachexia}

The pathophysiology of cardiac cachexia (CC) is complex and multifactorial including several factors interacting in a complex system with immune, metabolic, and neurohormonal consequences, which induce catabolic and anabolic imbalance. $^{3}$ The overall net catabolic dominance in HF provokes systemic tissue wasting. ${ }^{11}$ Skeletal muscle loss may be the most clinically relevant aspect, as it determines physical capacity and symptomatic severity of HF. However, bone and fat compartment are also affected by global catabolic dominance. ${ }^{11-13}$ The final event in progressive tissue wasting in $\mathrm{HF}$ is a life-threatening $\mathrm{CC}$.

\section{Immune activation}

Increased circulating levels of pro-inflammatory cytokines characterized $\mathrm{HF}$, namely, tumour necrosis factor alpha (TNF- $\alpha$ ), interleukin-1, and interleukin-6. ${ }^{14-17}$ The rise of these inflammatory mediators seems to be combined with inadequately raised or even decreased levels of antiinflammatory mediators such as interleukin-10 and transforming growth factor beta $1 .^{18}$ The cause of immune activation is still uncertain. ${ }^{19}$

\section{Metabolic abnormalities}

Evidence is mounting that the abnormal and imbalanced metabolism represents an intrinsic aspect of HF pathophysiology, with fundamental symptomatic and prognostic implications. ${ }^{11}$ The concept of metabolic failure in HF include both impaired myocardial energy utilization and metabolic inefficiency at the systemic level. The key points in this concept are global anabolic blunting and insulin resistance and catabolic overactivity. ${ }^{20,21}$ Anabolic deficiency in HF patients induce loss of skeletal muscle mass and function. ${ }^{22}$ Men with $\mathrm{HF}$ showed reduced circulating testosterone and dehydroepiandrosterone sulfate, and its relation with decreased exercise capacity. $^{23,24}$ It is well known that anabolic steroids have a significant role in the quantitative and qualitative regulation of muscle fibre content, leading to increases in muscle mass and strength, as well as improvement in physical performance. ${ }^{25}$ The major anabolic hormones modulating protein metabolism in skeletal muscle include insulin, growth hormone (GH), and insulin-like growth factor 1 (IGF-1). ${ }^{16}$ It has been previously proved that insulin resistance may play an important role in skeletal muscle dysfunction in HF. ${ }^{20,26}$ Since IGF-1 has been shown to stimulate protein synthesis and to reduce protein degradation, changes in the GH/IGF-1 axis may impact the anabolic/catabolic balance in the wasting syndrome. ${ }^{27}$ Patients with HF-related systolic or diastolic dysfunction have significantly lower plasma levels of total IGF-1, but free IGF-1 is significantly higher than in healthy controls. Recently, the role of leptin and other adipokines in the process of body wasting has been questioned. ${ }^{28-30}$ Adiponectin, an adipokine with multiple metabolic actions, increases both locally and globally with HF severity and is highest in cachectic patients. ${ }^{31,32}$ Our recent findings may indicate a crosssectional metabolic association of increased serum adiponectin with reduced peripheral muscle mass and muscle strength in non-cachectic, non-diabetic, elderly HF patients. $^{33}$ Recent reports suggest the role of changes in small and large intestine function in HF in the pathogenesis of wasting. ${ }^{34,35}$ Furthermore, in patients with stable HF, the blood flow in the intestinal arteries is reduced and relates to CC. $^{36}$

\section{Neurohormonal abnormalities}

The hallmark of HF pathophysiology, as a response to impaired cardiac function, is a general neurohormonal activation via stimulation of the sympathetic nervous system, the renin-angiotensin-aldosterone axis, and the natriuretic peptide system. $^{37,38}$ Chronic autonomic sympathetic/ parasympathetic imbalance is a crucial element of HF pathophysiology. Both epinephrine and norepinephrine can cause a catabolic metabolic shift, leading to graded increase in resting energy expenditure in $\mathrm{HF}$ patients with $\mathrm{CC}^{37,38}$ Sustained sympathetic stimulation, as is seen in $\mathrm{HF}$, activates the reninangiotensin-aldosterone axis. $^{39}$ Studies have shown that Angiotensin II induces muscle wasting through multiple mechanisms: (i) increased oxidative stress via activation of NADPH oxidase; (ii) increased protein breakdown via reduced IGF-1 and increased cytokine signaling such as glucocorticoid and IL-6; (iii) reduced appetite via alteration in orexigenic/anorexigenic neuropeptide expression in the hypothalamus; (iv) impaired energy balance via inhibition of AMPK; and ( $v$ ) inhibition of satellite cell function and muscle regeneration. ${ }^{40}$

\section{Molecular basis of cachexia}

The molecular basis of cachexia is still poorly understood, and the lack of therapies is evident. ${ }^{41-43}$ Better understanding of molecular mechanisms of cachexia has provided potentially new treatment targets. Skeletal muscle wasting is 
a consequence of protein synthesis and degradation imbalance. Recent studies in CC have evaluated the ubiquitinproteasome pathway (UPP) and autophagy/lysosomal proteolytic pathways to better understand the process of muscle atrophy in $\mathrm{HF}^{43-45}$ The UPP plays a critical role in skeletal muscle wasting. Studies from many groups over the past years have indeed identified many components in the UPP that are induced in atrophying skeletal muscle. ${ }^{46}$ The UPP plays a crucial role in the breakdown of myofibrillar proteins. ${ }^{12,47}$ The overactivation of the UPP in the skeletal muscle of HF patients has been attributed to increased oxidative stress. ${ }^{48,49}$ Transcription factors activating the proteasome pathway include particularly the forkhead box class $\mathrm{O}$ and nuclear factor- $\mathrm{KB}$ (NF-KB) that drive increased expression of the E3 ubiquitin ligases muscle RING-finger protein (MuRF-1) and muscle atrophy F-box. ${ }^{46}$ Thus, inhibition of forkhead box class $O$ was found to induce hypertrophy by increasing protein synthesis. ${ }^{50}$ Additionally, one recent study demonstrated that angiotensin II induces skeletal muscle atrophy in part by increased muscle-enriched E3 ubiquitin-ligase muscle RING-finger (MuRF-1) expression, which may involve protein kinase-D. ${ }^{51}$ Along with overactivated UPP, autophagy and lysosomal protein breakdown are also increased. ${ }^{52}$ Unlike UPP, which removes short-living cytosolic and nuclear proteins, the autophagylysosome system accounts for degradation of long-living proteins and protein aggregates. There is direct evidence that autophagy signaling is increased in a CC rat model. ${ }^{45}$ Some other important molecular mechanisms of controlling muscle mass include: PI3K-AKT signalling, NF-KB, SMAD2 and SMAD3 in myostatin-enhanced and activin A-enhanced proteolysis. ${ }^{43}$

\section{Myostatin}

Myostatin, a member of the transforming growth factor beta superfamily, is an extracellular cytokine dominantly expressed in skeletal muscles, which is known to play the important role in the negative regulation of muscle mass. ${ }^{53,54}$ Myostatin appears to be a key player in the integrated physiology of muscle, fat, and bone. ${ }^{55} \mathrm{It}$ is unclear whether myostatin directly affects fat and bone, or indirectly via muscle. Myostatin has high affinity to the activin IIB receptor, and it has been shown that administration of soluble activin IIB receptor resulted in an improvement in body and muscle weights in mice. ${ }^{56}$ However, myostatin and the muscle atrophy F-box expression remained unaffected by both the $\mathrm{HF}$ and age. ${ }^{57}$

Regenerative capacity of skeletal muscle

Skeletal muscle has a remarkable ability to maintain its homeostasis against injury or wasting by activating a well orchestrated regenerative response to repair damaged myofibers. ${ }^{58}$ Injury leads to activation and proliferation of mitotically quiescent mononuclear cells; satellite cells, which form myoblasts, terminally differentiate and fuse to form multinucleated myotubes. ${ }^{59}$ Trials in aged muscle clearly indicate that systemic changes in chronic disease states strongly affect satellite cell regenerative capacity. Therefore, identifying mechanisms whereby chronic diseases lead to lower satellite cell function would have the therapeutic potential to reverse the reduction in muscle regeneration seen in cachexia conditions.

\section{Emerging biomarkers of cardiac cachexia}

Despite the high morbidity and mortality associated to CC, there are no universally accepted specific biomarkers for this condition, which makes its diagnosis and treatment difficult. $^{60-62}$ Currently, wasting assessment is limited only to quantification of muscle mass based on imaging and functional tests to quantify muscle function. However, all are expensive and only available at medical centers equipped to do so. In addition, such tests only allow for wasting detection, but not for patients at risk of developing muscle atrophy. ${ }^{63,64}$ Thus, the identification of reliable biomarkers that can be used in a cost-effective manner and could guide diagnosis and therapy in routine clinical practice and clinical trials is warranted. Several inflammatory, hormonal, and oxidative stress molecules have been suggested as serological markers of prognosis in CC but with doubtful success. As individual biomarkers may have limited sensitivity and specificity, multimarker strategies involving mediators of the biological processes modulated by CC may importantly contribute for the diagnosis and management of the disease, as well as for the establishment of new therapeutic targets. ${ }^{16,60,62}$ After a brief reminder on biomarkers, which were evaluated in the past (biomarkers of immune activation, metabolic biomarkers, and neurohormonal biomarkers), we will focus in this review on the analysis of the emerging biomarkers for $\mathrm{CC} /$ cachexia/sarcopenia proposed recently (Table 1), briefly highlighting the biological processes to which they are related.

\section{Biomarkers of immune activation}

Several markers of immune activation have been investigated in the syndrome of cachexia such as TNF- $\alpha$, soluble tumour necrosis factor receptors (sTNFRs), interleukin 1 beta, interferon $\gamma$, and interleukin $6 .{ }^{16,60,65} \mathrm{CC}$ is related to increased circulating levels of $T N F-\alpha^{66,67}$, which are involved in the activation of catabolic pathways, in particular of NF- $\kappa \beta$ signaling that up-regulates the transcription of members of the proteolytic UPP. $^{16}$

\section{Metabolic biomarkers}

Among multiple metabolic disturbances already evaluated in the previous section of this review, this paragraph will focus on adipokines known to be of high importance for regulation of body weight in CC. Plasma levels of the adipokines, 
Table 1. Biomarkers of cardiac and non-cardiac cachexia

\begin{tabular}{|c|c|c|c|c|c|}
\hline & Biomarker & Cardiac cachexia & References & Non-cardiac cachexia & References \\
\hline \multicolumn{6}{|l|}{ Biomarkers of immune activation } \\
\hline & TNF- $\alpha$ & $\uparrow$ & $16,38,60,65,68$ & $\uparrow$ & $171-175$ \\
\hline & sTNFRs & $\uparrow$ & 38,42 & $\uparrow$ & 40 \\
\hline & IL-1 & $\uparrow$ & 38,42 & $\uparrow$ & 171,175 \\
\hline & IL-6 & $\uparrow$ & $38,42,68$ & $\uparrow$ & 176,177 \\
\hline \multicolumn{6}{|l|}{ Metabolic biomarkers } \\
\hline & Adiponectin & $\uparrow$ & $31,33,68$ & $\uparrow$ & 178,179 \\
\hline & Leptin & $\uparrow$ & $28,69-71$ & $\uparrow$ & 180 \\
\hline & Insulin & $\uparrow$ & $11,26,181,182$ & $\uparrow$ & 183,184 \\
\hline & Testosterone/DHEA & $\downarrow$ & $22-24$ & 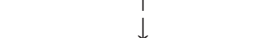 & 185 \\
\hline & Growth hormone & $\uparrow$ & $79,181,186,187$ & $\downarrow$ & 188,189 \\
\hline & IGF-1 & $\downarrow$ & $27,79,181$ & $\downarrow$ & 189,190 \\
\hline & Uric acid & $\uparrow$ & 11,191 & $\downarrow$ & 192 \\
\hline \multicolumn{6}{|l|}{ Neurohormonal biomarkers } \\
\hline & Norepinephrine & $\uparrow$ & $16,37,38$ & $\uparrow$ & 193 \\
\hline & Epinephrine & $\uparrow$ & $16,37,38$ & $\uparrow$ & 193 \\
\hline & Angiotensin II & $\uparrow$ & $40,72,73$ & $\uparrow$ & 74,75 \\
\hline & Natriuretic peptides & $\uparrow$ & 11,60 & $\uparrow$ & 77,194 \\
\hline & Cortisol & $\uparrow$ & $60,67,79,195$ & $\uparrow$ & 196 \\
\hline \multicolumn{6}{|l|}{ Emergent biomarkers } \\
\hline & Ghrelin & $\uparrow$ & $61,83,84$ & $\uparrow$ & $80,197,198$ \\
\hline & CAF & - & - & $\uparrow$ & 85,86 \\
\hline & GDF15 & - & - & $\uparrow$ & 88 \\
\hline & $\mathrm{IC6}$ and $\mathrm{C6M}$ & - & - & $\uparrow$ & 89,93 \\
\hline & P3NP & - & - & $\downarrow$ & 90 \\
\hline & Myostatin & $\uparrow \downarrow$ & $5,199-204$ & $* \downarrow * * \uparrow=$ & $\star 205 * * 55,206-209$ \\
\hline \multicolumn{6}{|l|}{ Markers of muscle mass } \\
\hline & Serum creatinine & - & - & $\downarrow$ & $93,210,211$ \\
\hline & Urinary creatinine & - & - & $\downarrow$ & 95 \\
\hline & Gelsolin & - & - & $\downarrow$ & 96 \\
\hline
\end{tabular}

C6M, MMP-generated degradation fragment of collagen 6; CAF, C-terminal agrin fragment; CC, cardiac cachexia; DHEA, Dehydroepiandrosterone; GDF15, growth differentiation factor 15; IC6, type VI collagen N-terminal globular domain epitope; IGF-1, Insulin-like growth factor 1; IL-1, Intereleukin 1; IL-6, Interleukin 6; P3NP, N-terminal propeptide of type III procollagen; sTNFRs, Soluble tumour necrosis factor receptors (sTNFRs); TNF- $\alpha$, tumour necrosis factor alpha.

*Circulating myostatin levels in non-cardiac cachexia;

** Local myostatin expression in non-cardiac cachexia.

- , no trials to date.

adiponectin, and leptin may have a role in the detection of muscle, fat, and bone wasting processes. ${ }^{12,32}$ Adiponectin may play a role in the pathogenesis of body wasting among HF patients. ${ }^{13,33,68}$ The catabolic effects of leptin include inhibition of insulin signaling and enhanced lipid oxidation, thus inhibiting anabolic pathways and reducing energy storage. ${ }^{69}$ These effects may have catabolic effects promoting the development of CC in HF patients. ${ }^{70}$ Interestingly, leptin levels decrease in CC, but remain higher than in healthy individuals. ${ }^{71}$ This decrease in leptin concentrations may be due to the reduction of fat tissue in these patients. ${ }^{70,71}$

\section{Neurohormonal biomarkers}

Both norepinephrine and epinephrine, as mediators of activated sympathetic nervous system, cause a metabolic shift towards catabolism, leading to a graded increase in resting energy expenditure in patients with $\mathrm{CC}^{16}$ Ang II-induced body wasting is due to both anorexigenic and catabolic effects. ${ }^{72,73}$ Recently, Cichello et al. ${ }^{74}$ showed a direct effect of Ang II infusion on appetite impairment and body weight loss mostly due to adipose tissue wasting. Sanders et al. ${ }^{75}$ have reported a direct catabolic effect on skeletal muscle by Ang II with increased intracellular protein degradation in murine myotubes through an increased expression of the UPP. Increased plasma levels of atrial natriuretic peptide and brain natriuretic peptide were found in cachectic HF patients when compared with non-cachectic patients and healthy volunteers. ${ }^{60,66}$ The role of the heart in metabolism is highlighted by the lipolytic activity of natriuretic peptides, as well as by its actions on slowing gastric emptying and absorption. ${ }^{76,77}$ The inverse correlation reported between natriuretic peptides and body weight index seems to be explained by the increased energy utilization and thermogenesis induced by these peptides. ${ }^{78}$ Plasma cortisol levels are increased in CC patients. ${ }^{60,67,79}$ Cortisol is known to induce muscle atrophy by decreasing protein synthesis and increasing proteolysis by four distinct mechanisms.

\section{Novel biomarkers for cardiac cachexia/cachexia}

\section{Ghrelin}

Ghrelin is a 28-amino acid peptide hormone monal tissues. ${ }^{80}$ It stimulates the release of growth hormone from the 
pituitary gland and stimulates food intake. ${ }^{80,81}$ Ghrelin is a strong adipogenic and orexigenic molecule, inducing weight gain and adiposity. ${ }^{82}$ Ghrelin not only suppresses the production of the pro-inflammatory cytokines tumour necrosis factor, interleukin-1 $\beta$, and interleukin-6, but also stimulates the anti-inflammatory cytokine interleukin-10. ${ }^{60}$ In general, the metabolic changes induced by ghrelin lead to an increase not only in body weight and body fat mass, but also in lean tissue mass, the latter possibly mediated by a reduction in myostatin plasma levels. ${ }^{61}$ The resistance of $\mathrm{HF}$ patients to the effects of appetite-stimulating peptide ghrelin may be one of the contributing factors in the development of $\mathrm{CC}^{83}$ Patients with HF and CC have higher plasma ghrelin levels than in those without CC and healthy subjects, which may suggest a compensatory mechanism under the conditions of anabolic/catabolic imbalance, countering further energy deficit and defending against starvation. ${ }^{84}$

C-terminal agrin fragment (CAF): CAF, derived from the peptide agrin, is a synaptically located key player during the initial formation and maintenance of neuromuscular junctions. ${ }^{46}$ In humans, serum CAF levels have recently been shown to be inversely related to appendicular lean mass in men where lower appendicular lean mass was associated with higher CAF. ${ }^{85}$ In addition, serum CAF concentrations have been shown to be increased in older adults with sarcopenia compared with aged-matched controls. ${ }^{86}$ Resistance exercise training significantly improves muscle strength and quality in older adults and results in an increase of CAF in older adults. ${ }^{87}$ It has been proposed as a novel diagnostic marker for muscle wasting in HF patients, which may be useful in identifying patients with $\mathrm{CC} .^{42}$

Growth differentiation factor 15 (GDF-15): Several studies have shown that GDF-15 plays an important role in the pathways of muscle wasting and cachexia. ${ }^{46,88}$ Recent findings suggest that GDF-15 induces weight, fat, and muscle wasting, as well as that it decreases activity in mice and may be a promising target for therapeutic interventions in the field of cachexia. $^{88}$

\section{IC6 and C6M}

One recent study showed that type $\mathrm{VI}$ collagen turnoverrelated peptides (IC6 and C6M) represent novel biomarkers of muscle mass or change in muscle mass in young men. ${ }^{89}$ Type $\mathrm{VI}$ collagen is a basement membrane protein expressed in most tissues, but highly abundant in muscle sarcolemma. ${ }^{90}$

\section{P3NP}

This collagen fragment $N$-terminal propeptide of type III procollagen (P3NP) is a measure of skeletal muscle status and a biomarker candidate for muscle anabolism. ${ }^{87}$ It is released into circulation during collagen synthesis in soft lean tissue, and its levels have been associated with changes in the lean mass of elderly patients. ${ }^{63,91}$
Myostatin

Although it seems a natural candidate for an atrophy biomarker, as it directly mediates catabolic signaling, the data of a recent study in CC could not confirm the role of circulating myostatin as a biomarker for muscle wasting in humans. ${ }^{12,63,92}$

\section{Biomarkers of muscle mass}

Serum creatinine levels are understood to be an unspecific marker of muscle wasting. ${ }^{93}$ Most studies show that serum creatinine correlate well with measures of skeletal muscle mass. ${ }^{93,94}$ Low urine creatinine excretion, as an indirect measure of low muscle mass, is associated with major adverse cardiac events and all-cause mortality in the general population. ${ }^{95}$ Plasma gelsolin is an actin-binding protein mainly produced and secreted by myocytes. ${ }^{96}$ Recent data demonstrated the prognostic ability of low plasma gelsolin concentrations in hemodialysis patients suggesting that its levels incorporate the degree of systemic inflammation and muscle wasting. ${ }^{96,97}$ Plasma gelsolin has been suggested as a marker of muscle mass in haemodialysis patients. ${ }^{93,98}$

\section{Therapeutic strategies for cardiac cachexia}

The development of preventive and therapeutic strategies against cachexia, sarcopenia, and wasting disorders is perceived as an urgent need by healthcare professionals. ${ }^{99,100}$ However, the treatment of skeletal muscle wasting remains an unresolved challenge to this day. As CC is a multifactorial disorder, it is unlikely that any single agent will be completely effective in treating this condition; thus, it will be necessary to target different pathways. Figure 1 summarizes some potential therapeutic strategies in the management of CC.

\section{Preventive strategies for body wasting and cardiac cachexia}

Heart failure (HF) management improved over the last decades, and key pharmacological agents are now prescribed to most patients. ${ }^{101} \mathrm{We}$, however, keep under treating our patients, particularly with beta blockers but also with ACE inhibitors. When considering the landmark report of ACE inhibitor associated prevention of weight loss, ${ }^{102}$ the adequate daily dose should be pursued. For beta blockers, the disproportion is even greater as less than $20 \%$ of patients receive target daily dose. ${ }^{101}$ As weight gain is the class effect of beta blockers, it is not surprising that in $\mathrm{HF}$, carvedilol was associated with prevention of $6 \%$ weight loss (risk reduction vs placebo: $33 \%$ ) and with $>5 \%$ weight gain ( $37 \%$ vs. placebo). Recently, some ACE inhibitors and beta blockers have been 
Figure 1 Therapeutic strategies in the management of cardiac cachexia

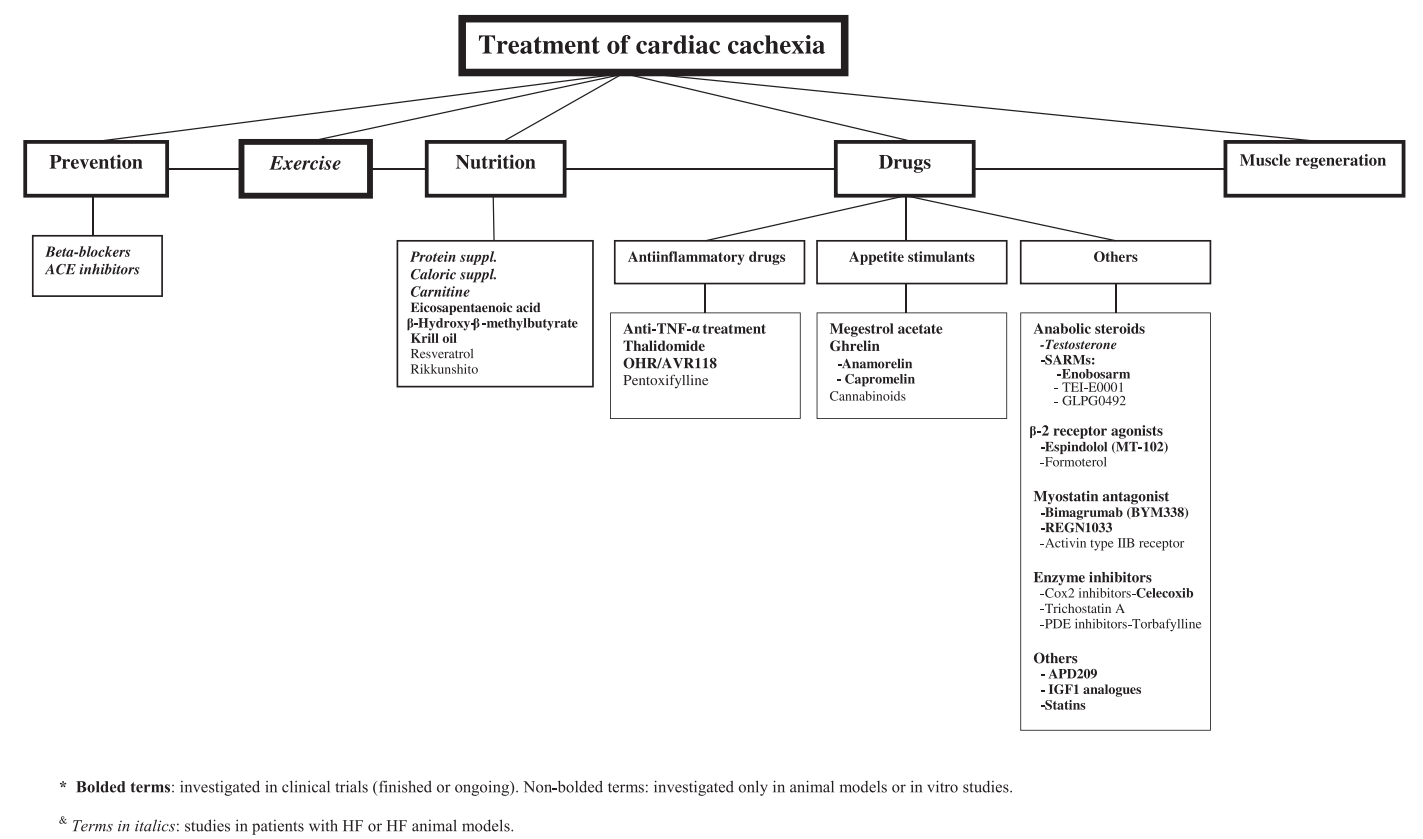

tested for the potential of muscle mass gain. Imidapril, a highly lypophylic ACE inhibitor, was tested in a mice tumour model. At a daily dose of $10 \mathrm{mg} / \mathrm{kg}$ body weight, it attenuated the weight loss. ${ }^{75}$ Similar effects were observed in another experiment performed in the murine cancer cachexia model, where imidapril attenuated the muscle and adipose tissue depletion. ${ }^{103}$ Transfer to patients with cancer cachexia was already conducted in a randomized placebo controlled trial, but the findings were not published yet. ${ }^{104}$ Another attractive concept for prevention of body wasting is the exercise training that is expanding over a variety of chronic disease, including the cachexia patients. ${ }^{105}$

\section{Exercise training}

Being a part of daily living, exercise is the easiest way to preserve and increase muscle mass; also, it is the most effective anabolic agent with many ancillary effects delivered at no or low costs. Data are now emerging for patients with chronic kidney disease $\mathrm{e}^{106-108}$ and cancer, ${ }^{109}$ while there are already existing guidelines for $\mathrm{HF}^{110}$ and chronic obstructive pulmonary disease. ${ }^{111}$ The current gold standard against muscle wasting is exercise training. ${ }^{112}$ Among all investigated therapeutic strategies, aerobic exercise training (AET) in $\mathrm{HF}$ patients is the most proved to counteract skeletal muscle wasting and is recommended by treatment guidelines for HF. ${ }^{58,113}$ However, in the paper of Moreira et al., the benefits of AET on skeletal muscle mass, metabolic capacity, and proteasome activity changes were remarkably similar between protocols. ${ }^{114}$ Thus, future efforts are warranted to evaluate the AET protocols (e.g. durations, types, different intensities) in order to optimize the effects of AET on CC.

\section{Nutritional interventions}

The influence of nutrition on protein kinetics in patients with cachexia is poorly understood. ${ }^{46}$ Nutritional therapy alone has no effect on the underlying catabolic process of cachexia, but it would be interesting to know the potential synergistic effect from nutritional therapy in conjunction with different drugs. There is increasing evidence that protein supplementation acts to increase muscle synthesis and that this effect is increased in conjunction with exercise. ${ }^{115}$ The international study group to review dietary protein needs with aging (The PROTAGE study group) has supported the need for $1-1.5 \mathrm{~g} / \mathrm{kg}$ of high-quality protein to restore muscle in persons with sarcopenia. ${ }^{116}$ Additionally, caloric supplementation in $\mathrm{HF}$ patients enhanced weight and improved quality of life. ${ }^{117}$ Skeletal and cardiac muscle creatine content is reduced in $\mathrm{HF}$, largely because of reduced expression of the creatine-sodium co-transporter. ${ }^{11}$ Although there is some evidence of improved skeletal muscle function and exercise duration with chronic oral carnitine administration, there is no evidence of improved cardiac function. ${ }^{118}$ Some nutritional interventions such as eicosapentaenoic acid, $\beta$-Hydroxy- $\beta$-methylbutyrate, and resveratrol may counteract body wasting and muscle loss in animal models, without proved effects in humans. ${ }^{119}$ 


\section{Rehabilitation nutrition}

The concept of rehabilitation nutrition as a combination of both rehabilitation and nutrition care management may improve muscle mass and physical performance in disabled elderly. ${ }^{120}$ One recent study in HF patients showed that the combination of branched chain amino acid (BCAA) supplementation and resistance exercise can manage sarcopenia and cachexia. ${ }^{121}$ The authors found that clinical and physical improvements were caused by the resistance exercise independently from branched chain amino acid supplementation. In general, there is consensus that sarcopenia requires appropriate physical therapy and nutrition management in addition to treatment for primary disease. ${ }^{120}$

\section{Drugs for cardiac cachexia}

Clinical trials with drugs in the field of cachexia remain small, and most are performed in oncology patients. ${ }^{61}$ Investigations of drugs that counteract body wasting in $\mathrm{HF}$ patients are scarce. About 19 drugs that can regulate muscle mass have been reported in the literature so far. ${ }^{119}$ These therapeutic interventions include use of anti-inflammatory substances and appetite stimulants. Except megestrol, no other drug has yet been recommended by the FDA to prevent or treat muscle atrophy.

\section{Anti-inflammatory drugs}

\section{Anti-TNF- $\alpha$ treatment}

Use of antibodies against pro-inflammatory cytokines could be beneficial in regulating loss of skeletal muscle. There are many studies that have highlighted the beneficial effect of some of these antibodies such as anti-TNF $\alpha$, anti-IL-1, and anti-IL-6 on preserving the muscle loss and restoring their function. ${ }^{119}$ Some of these antibodies are under phase I/II/ III trials predominantly in patients with cancer cachexia. One animal study showed that anti-TNF $\alpha$ treatment reduces the skeletal muscle wasting in cardiac cachexia and preserves the body mass ${ }^{122}$.

Thalidomide has shown its anti-cachectic property in cancer patients by down-regulating the TNF $\alpha$ mRNA expression. It also prevents the nuclear translocation of NF- $\mathrm{KB}$ along with reduction of serum levels of IL- 6 and CRP in the cancercachexia patients. ${ }^{123,124}$

Pentoxifylline is also known as suppressor of TNF production, and this property makes it helpful in prevention of skeletal muscle wasting in cancer, sepsis, trauma, and AIDS models. ${ }^{125,126}$

OHR/AVR118 is a broad-spectrum peptide-nucleic acid immune-modulator with anti-inflammatory activity that targets both cellular pro-inflammatory chemokine and cytokine synthesis (such as TNF- $\alpha$ and IL-6). A phase II trial of this drug on patients with advanced cancer and cachexia achieved stabilization of body weight, body fat, and muscle mass with a significant increase in appetite without showing any adverse effect. ${ }^{127}$ Additionally, this drug has also been used for treatment of AIDS cachexia patients. ${ }^{119}$

Appetite stimulants

Megestrol acetate

Previous studies have shown beneficial results in humans with cancer cachexia using appetite stimulants such as megestrol acetate (with or without thalidomide, formoterol, and L-carnitin) to improve skeletal muscle mass and strength. ${ }^{128-130}$ Beginning in 1993, megestrol acetate was approved in the USA and in several European countries for the treatment of the anorexia-cachexia syndrome. ${ }^{131}$ The precise mechanism by which weight gain is mediated is unknown, but studies suggest the role of neuropeptide $Y$, the inhibition of pro-inflammatory cytokines, and the modulation of calcium channels in the ventromedial hypothalamus. ${ }^{132-134}$

Cannabinoids are known to stimulate appetite as well. ${ }^{65}$ The mechanism by which cannabinoids exert their effects is not elucidated, but it was suggested that they may act via endorphin receptors, by inhibiting prostaglandin synthesis, or may suppress cytokine production and/or secretion. ${ }^{135,136}$

Ghrelin administration has therapeutic appeal for its anabolic activities. ${ }^{137}$ Ghrelin agonists such as anamorelin carry potential in the treatment of cachexia as they mimic a natural ligand for the growth hormone secretagogue receptor and thus stimulate food intake and appetite. ${ }^{21}$ The single study in humans showed that repeated administration of ghrelin improved left ventricular function, exercise capacity, and muscle wasting in patients with HF. ${ }^{138}$ In the recent study in patients with lung carcinoma and cachexia, anamorelin significantly increased body weight, improved muscle strength and quality of life, and had an overall favourable safety/tolerability profile. ${ }^{139}$ The largest human trial with anamorelin intervention ROMANA 2 phase III trial that included 495 patients with non-small cell lung cancer was recently finished, but results have not been reported so far. ${ }^{140}$ Another study have shown that the ghrelin agonist, capromelin, increased lean mass and physical performance over one year in older sarcopenic individuals. ${ }^{141}$

Other drugs for treatment of cardiac cachexia/non-cardiac cachexia

Anabolic steroids including testosterone have been effectively used to treat muscle wasting in $\mathrm{HF}^{22}$ The problem with the administration of anabolic steroids are adverse events that outweigh their potential benefits. Selective androgen receptor modulators (SARMS) belong to a relatively new class of therapeutics currently under development that possesses anabolic properties without adverse effects on prostate, skin, or hair frequently associated with testosterone treatment. ${ }^{56,142}$ 
Enobosarm, an orally bioavailable non-steroidal SARM with tissue-specific anabolic and androgenic activity, has shown amelioration in lean mass and physical function in healthy younger as well as in healthy elderly men and postmenopausal women. ${ }^{143,144}$ In patients with cancer, treatment with enobosarm confirmed its beneficial effect on skeletal muscle mass and physical performance. ${ }^{145}$ Dobs et al. established a SARM, enobosarm, as a new drug for the prevention and treatment of muscle wasting in cancer patients. ${ }^{146}$ Takagi et al. recently presented another new SARM (TEI-E0001) as a novel long acting SARM. ${ }^{147}$ In the animal model, they demonstrated that TEI-E0001 has potent anabolic activity on the muscle and bone, while reducing androgenic side effects. GLPG0492(galapagos) is another non-steroidal SARM that has shown its efficacy on muscle by increasing muscle fibre size and skeletal muscle function in the hind limb of immobilized mice and in Duchenne muscular dystrophy patients, respectively. ${ }^{148,149}$

\section{$\beta-2$ receptor agonists}

$\beta-2$ receptor agonism is involved in the regulation of skeletal muscle proliferation and differentiation programmes, and these properties make this receptor signaling pathway a novel therapeutic target for controlling the skeletal muscle wasting. ${ }^{150,151} \mathrm{~A}$ novel anabolic agent espindolol (MT-102) has recently been established. Animal experiments in 19month-old male Wistar Han rats have shown that espindolol can abolish the effects of ageing-related body and muscle wasting. ${ }^{152}$ It appears to possess three potential pharmacological targets in cancer cachexia: (i) reduced catabolism through non-selective $\beta$-blockade, (ii) reduced fatigue and thermogenesis through central 5-HT1a antagonism, and (iii) increased anabolism through partial $\beta-2$ receptor agonism. ${ }^{153}$ The ACT-ONE trial has recently demonstrated that MT-102 counteracted body wasting and some aspects of physical performance in 87 patients with cancer cachexia. ${ }^{46,154}$ Another $\beta-2$ receptor agonist, formoterol, induced reduction of muscle weight loss in cachectic tumour-bearing rats and showed no influence on heart weight and seems to improve heart function. ${ }^{155}$ Thus, MT-102 and formoterol seem to be prospective new drugs to treat patients with cancer cachexia, especially if they present signs of declined cardiac function. ${ }^{46}$

\section{Myostatin antagonist}

REGN1033 and Bimagrumab (BYM338) are two human mono-clonal antibodies against myostatin. ${ }^{119}$ The administration of myostatin antagonist (REGN1033) induced increase of muscle mass, force, and physical performance outcomes in aged mice and prevents the loss of muscle mass. ${ }^{156}$ The treatment with BYM338 enhances differentiation of primary human skeletal myoblasts and increases skeletal muscle mass in mice by blocking the activin type II B receptors (ActRIIB). ${ }^{119}$ A soluble form of the activin type IIB receptor (ActRIIB/Fc; ACVR2B-ACE031) can inhibit myostatin signalling and significantly increases muscle growth in mice bearing cancer. ${ }^{157}$ Overall BYM338, REGN1033, and soluble ActRIIB/Fc are promising drugs that have the ability to regulate muscle wasting/cachexia by blocking myostatin/activin signaling under diverse pathological conditions including cancer.

\section{Enzyme inhibitors}

Several enzyme inhibitors (Cox2 inhibitors, Trichostatin A,PDE inhibitors-torbafylline) showed promising results in suppressing muscle loss in animal models of cachexia. ${ }^{119}$ Additionally, Cox2 inhibitor, celecoxib has showed a beneficial effect against muscle loss in patients with cancer and arthritis-induced cachexia.

\section{IGF1 analogues}

'Long arginine' IGF1 is a modified form of IGF1 that has a long circulation time, binds to more tissue targets and is more potent than endogenous IGF1. ${ }^{43}$ Its ability to induce myoblast proliferation offers greater therapeutic potential. However, several more potent variants have been developed that have prolonged circulation times and have reduced association with inhibitory IGF1? binding proteins. ${ }^{158}$

\section{APD209}

APD209 is an oral, fixed-dose combination of megestrol and formoterol for use in treatment of cancer cachexia at the moment. ${ }^{119}$

\section{Statins}

Along with the primary effect of cholesterol lowering, statins have many ancillary actions that may be relevant for body wasting. ${ }^{65}$ In this context, the fear of muscle-related side effects needs to be put into clinical context and assessed appropriately before statins are either withheld or withdrawn in patients with sarcopenia/cachexia. ${ }^{159}$ In fact, several reports suggest statins may even have beneficial effects by preserving or even increasing body compartments (muscle and fat). In an animal model of cancer cachexia, simvastatin vs. placebo attenuated body weight loss (28-48\%, depending on dose, $P<0.05$ for all), mainly because of the preservation of muscle mass. ${ }^{160}$ With the improvement of cardiac function, this translated into improved survival with simvastatin. Statins were also associated with an increase of lean mass as measured by DEXA following 12 week resistance training. ${ }^{161}$ Lean mass gain was higher in those subjects who had higher dietary cholesterol intake and higher serum cholesterol.

\section{Muscle regeneration}

One theoretical approach is to use stem cells to help replace degenerated muscle tissue. ${ }^{92}$ Recent studies demonstrated different types of stem cells that have been attributed to be endowed with muscle regenerative potential. ${ }^{59,162}$ The possibility to reprogram all the cells of the body to muscle presents a revolutionary concept, importantly widening the range of muscle sources for the treatment of muscle dysfunction. 
Ventricular assist device

The improvement of cardiovascular circulatory support by ventricular assist device in terminal $\mathrm{HF}$ patients corrects GH/IGF-1 signaling along with amelioration of muscle structure and function with enhancement of oxidative muscle metabolism. ${ }^{163}$

\section{Gaps in evidence-based management of body wasting and cachexia}

To improve design of interventional trials, we need to gain better insight into epidemiology, trajectories, and pathways of body wasting in chronic disease. It is not irrelevant how and why the patients die. ${ }^{164}$ Knowing the most common causes and also modes of death can lead to application of well-established therapies, e.g. beta blockers or devices for sudden cardiac death. Body wasting and cachexia are usually recognized when patients experience certain limitations in activities of daily living; at this stage, underlying mechanisms are well advanced and tissue damage is already present. Biomarkers that could pick up the changes before they convey into clinical manifestations would be of great importance. For these purposes, blood and/or urine analysis is attractive, with several candidates to assess muscle wasting and quality that are in clinical testing. ${ }^{87,89,165}$ The complex biochemical network related with CC and HF pathophysiology underlines that a single biomarker cannot reflect all of the features of the disease. Consequently, future studies should be focused on the use of a combination of multiple biomarkers in order to establish an optimal network that better reflects all of the characteristic of the syndrome. As there is up-regulation of proteolysis in CC, it is expected an augmentation of cleavage products from proteases as caspases, calpains, or cathepsins. $^{60,166}$ Its measurement may more specifically express cachectic biological processes leading to fatal outcome. In addition to proteolysis, other protein modifications such as oxidation as a result of oxidative stress, ${ }^{60,166}$ which also should be considered in the definition of multimarker strategies. Finally, whether use of proteomics and metabolomics analysis may contribute in better biomarker evaluation of CC is still unknown as this has not been still assessed in that condition.

A better understanding of pathophysiological pathways in body wasting will contribute to establish potentially novel treatment strategies. Whether the use of microdyalisis on skeletal muscle may be of help in regard to this aim will be soon evaluated in our study in acutely decompensated HF patients. Microdialysis is a technique designed to explore and monitor the chemistry of extracellular fluid of virtually any tissue or cell culture medium. ${ }^{167}$

The intriguing concept to reprogram all the cells of the body to muscle presents a revolutionary idea, importantly widening the range of muscle sources for the treatment of muscle dysfunction. ${ }^{59}$ Further studies are warranted on the potential of stem cell therapy to counteract the muscle wasting including identification of mechanisms whereby chronic disease lead to lower satellite cell function that would have the therapeutic potential to reverse the reduction in muscle regeneration seen in cachexia conditions.

The scientific community is much engaged in interventional trials to find a remedy for muscle wasting and cachexia. It should be emphasized that translation of benefits from the non-cachectic population to cachexia may not be straightforward as drug pharmacokinetics changes with body wasting. ${ }^{168,169}$ Ongoing trials are heterogenous in design and include a wide span of chronic disease. ${ }^{94,112} \mathrm{~A}$ direct comparison of findings will be difficult as enrolment criteria (including sarcopenia/cachexia definition) vary and because different endpoints are being pursued. On top of that, different analysis plans are used for different regulatory authorities. Many experts have called for a unified approach, and their notion has now materialized in a consensus document. ${ }^{170}$ Following this guidance, better use of available resources for adequately powered trials with meaningful clinical endpoints is anticipated. Most of the candidate compounds are newly developed; thus, safety issues deserve particular attention. This should not be limited only to acute side effects but also to drug-drug interactions and long-term safety profile.

\section{Conclusions}

Cardiac cachexia (CC) is the clinical entity at the end of the chronic natural course of HF. A simplistic view could be that with effective prevention, incidence of CC would be low or non-existing. In the real world, multiple factors influence disease trajectories in this syndrome. Detection of the pathways that modulate muscle wasting and dysfunction will provide important information for the definition of CC-specific biomarkers and for the development of medications that counteract muscle impairment, which will certainly improve the treatment of this serious disorder.

\section{Acknowledgements}

The authors certify that they comply with the ethical guidelines for authorship and publishing of the Journal of Cachexia, Sarcopenia and Muscle. ${ }^{212}$ This paper was also published in parallel in the International Journal of Cardiology.

\section{Conflict of interest}

None declared. 


\section{References}

1. Farkas J, von Haehling $\mathrm{S}$, Kalantar-Zadeh K, Morley JE, Anker SD, Lainscak M. Cachexia as a major public health problem: frequent, costly, and deadly. I Cachexia Sarcopenia Muscle 2013;4: 173-8.

2. von Haehling S, Anker SD. Cachexia as a major underestimated and unmet medical need: facts and numbers. I Cachexia Sarcopenia Muscle 2010;1: 1-5.

3. Evans WJ, Morley JE, Argile's J, Bales C, Baracos V, Guttridge D, et al. Cachexia: a new definition. Clin Nutr 2008;27: 793-9.

4. von Haehling S, Anker SD. Prevalence, incidence and clinical impact of cachexia: facts and numbers-update 2014. J Cachexia Sarcopenia Muscle 2014;4: 261-3.

5. Christensen HM, Kistorp C, Schou M Keller N, Zerahn B, Frystyk J, et al. Prevalence of cachexia in chronic heart failure and characteristics of body composition and metabolic status. Endocrine 2013;43: 626-34.

6. Letilovic T, Vrhovac R. Influence of additional criteria from a definition of cachexia on its prevalence - good or bad thing? Eur J Clin Nutr 2013;67: 797-801.

7. Arthur ST, Noone JM, van Doren BA, Roy $D$, Blanchette CM. One-year prevalence, comorbidities and cost of cachexiarelated inpatient admissions in the USA. Drugs Context 2013;3: 212265.

8. von Haehling S, Lainscak M, Doehner W, Ponikowski P, Rosano G, Jordan J, et al. Diabetes mellitus, cachexia and obesity in heart failure: rationale and design of the Studies Investigating Co-morbidities Aggravating Heart Failure (SICA-HF). J Cachexia Sarcopenia Muscle 2010;1: 187-94.

9. Fülster S, Tacke $M$, Sandek A, Ebner N, Tschöpe C, Doehner W, et al. Muscle wasting in patients with chronic heart failure: results from the studies investigating co-morbidities aggravating heart failure (SICA-HF). Eur Heart J 2013;34: 512-9.

10. Del Fabbro E, Jatoi A, Davis M, Fearon K, di Tomasso J, Vigano A. Health professionals' attitudes toward detection and management of cancer-related anorexiacachexia syndrome, and a proposal for standardized assessment. J Community Support Oncol 2015;13: 181-7.

11. Doehner $W$, Frenneaux M, Anker SD. Metabolic impairment in heart failure: the myocardial and systemic perspective. J Am Coll Cardiol 2014;64: 1388-400.

12. Loncar G, Fülster $S$, von Haehling $S$, Popovic V. Metabolism and the heart: an overview of muscle, fat, and bone metabolism in heart failure. Int $J$ Cardiol 2013;162: 77-85

13. Bozic B, Loncar G, Prodanovic N, Radojicic Z, Cvorovic V, Dimkovic S, et al. Relationship between high circulating adiponectin with bone mineral density and bone metabolism in elderly males with chronic heart failure. J Card Fail 2010;16: 301-7.

14. Levine B, Kalman J, Mayer L, Fillit HM, Packer M. Elevated circulating levels of tumor necrosis factor in severe chronic heart failure. $N$ Engl J Med 1990;323: 236-41.

15. McMurray J, Abdullah I, Dargie HJ, Shapiro D. Increased concentrations of tumour necrosis factor in "cachectic" patients with severe chronic heart failure. Br Heart J 1991;66: 356-8.

16. Martins T, Vitorino R, Moreira-Gonçalves D, Amado F, Duarte JA, Ferreira R. Recent insights on the molecular mechanisms and therapeutic approaches for cardiac cachexia. Clin Biochem 2014;47: 8-15.

17. von Haehling S, Schefold JC, Lainscak M, Doehner W, Anker SD. Inflammatory biomarkers in heart failure revisited: much more than innocent bystanders. Heart Fail Clin 2009;5: 549-60.

18. Aukrust $\mathrm{P}$, Ueland $\mathrm{T}$, Lien $\mathrm{E}$, Bendtzen $\mathrm{K}$, Müller $F$, Andreassen AK, et al. Cytokine network in congestive heart failure secondary to ischemic or idiopathic dilated cardiomyopathy. Am J Cardiol 1999;83: 376-82.

19. Jankowska EA, Ponikowski P, Piepoli MF, Banasiak W, Anker SD, Poole-Wilson PA. Autonomic imbalance and immune activation in chronic heart failure-pathophysiological links. Cardiovasc Res 2006;70: 434-45.

20. Szabo $T$, von Haehling $S$, Habedank $D$, Rauchhaus M, Lainscak M, Sandek A, et al. Usefulness of minimal modelling to assess impaired insulin sensitivity in patients with chronic heart failure. Int Cardiol 2011;147: 47-51.

21. Coats AJ. Research on cachexia, sarcopenia and skeletal muscle in cardiology. J Cachexia Sarcopenia Muscle 2012;3: 219-23.

22. Josiak K, Jankowska EA, Piepoli MF, Banasiak W, Ponikowski P. Skeletal myopathy in patients with chronic heart failure: significance of anabolic-androgenic hormones. J Cachexia Sarcopenia Muscle 2014;5: 287-96.

23. Jankowska EA, Filippatos G, Ponikowska B, Borodulin-Nadzieja L, Anker SD, Banasiak W, et al. Reduction in circulating testosterone relates to exercise capacity in men with chronic heart failure. J Card Fail 2009;15: 442-50.

24. Jankowska EA, Biel B, Majda J, Szklarska A, Lopuszanska M, Medras M, et al. Anabolic deficiency in men with chronic heart failure: prevalence and detrimental impact on survival. Circulation 2006;114: 1829-37.

25. Kadi F. Cellular and molecular mechanisms responsible for the action of testosterone on human skeletal muscle. A basis for illegal performance enhancement. $\mathrm{Br} \mathrm{J}$ Pharmacol 2008;154: 522-8.

26. Scherbakov N, Bauer M, Sandek A, Szabó $\mathrm{T}$, Töpper A, Jankowska EA, et al. Insulin resistance in heart failure: differences between patients with reduced and preserved left ventricular ejection fraction. Eur J Heart Fail 2015;doi:10.1002/ ejhf.317.

27. Brink M, Anwar A, Delafontaine P. Neurohormonal factors in the development of catabolic/anabolic imbalance and cachexia. Int J Cardiol 2002;85: 111-21.

28. Singh $M$, Bedi US, Singh PP, Arora R, Khosla S. Leptin and the clinical cardiovascular risk. Int J Cardiol 2010;140: 266-71.

29. Araujo JP, Lourenco P, Rocha-Goncalves $F$, Ferreira A, Bettencourt P. Adiponectin is increased in cardiac cachexia irrespective of body mass index. Eur J Heart Fail 2009;11: 567-72.

30. Tedeschi S, Pilotti E, Parenti E, Vicini V, Coghi P, Montanari A, et al. Serum adipokine zinc alpha-2 glycoproteinand lipolysis in cachectic and noncachectic heart failure patients: relationship with neurohormonal and inflammatory biomarkers. Metab Clin Exp 2012;61: 37-42.

31. Kistorp C, Faber J, Galatius S, Gustafsson F, Frystyk J, Flyvbjerg A, et al. Plasma adiponectin, body mass index, and mortality in patients with chronic heart failure. Circulation 2005;112: 1756-62.

32. Szabó $T$, Scherbakov N, Sandek A, Kung $T$, von Haehling S, Lainscak M, et al. Plasma adiponectin in heart failure with and without cachexia: catabolic signal linking catabolism, symptomatic status, and prognosis. Nutr Metab Cardiovasc Dis 2014;24: 50-6.

33. Loncar $G$, Bozic $B$, von Haehling $S$, Düngen HD, Prodanovic N, Lainscak M, et al. Association of adiponectin with peripheral muscle status in elderly patients with heart failure. Eur J Intern Med 2013;24: 818-23.

34. Sandek A, Valentova $M$, von Haehling $S$, Doehner W, Anker SD. The small intestine: a critical linkage in pathophysiology of cardiac cachexia. Int J Cardiol 2011;146: 277-8.

35. Celik T, Iyisoy A, Yuksel UC, Jata B. The small intestine: a critical linkage in pathophysiology of cardiac cachexia. Int J Cardiol 2010;143: 200-1.

36. Sandek A, Swidsinski A, Schroedl W, Watson A, Valentova M, Herrmann R, et al. Intestinal blood flow in patients with chronic heart failure: a link with bacterial growth, gastrointestinal symptoms, and cachexia. J Am Coll Cardiol 2014;64: 1092-102.

37. Anker SD, Sharma R. The syndrome of cardiac cachexia. Int J Cardiol 2002;85: 51-66.

38. Anker SD, Coats AJS. Cardiac cachexia*a syndrome with impaired survival and immune and neuroendocrine activation. Chest J 1999;115: 836-47.

39. Ferrara R, Mastrorilli F, Pasanisi G, Censi $\mathrm{S}$, D'aiello $\mathrm{N}$, Fucili $\mathrm{A}$, et al. 
Neurohormonal modulation in chronic heart failure. Eur Heart J Suppl 2002;4: D3-D11.

40. Yoshida T, Delafontaine P. Mechanisms of cachexia in chronic disease states. Am J Med Sci 2015;350: 250-256.

41. Fearon KC, Glass DJ, Guttridge DC. Cancer cachexia: mediators, signaling, and metabolic pathways. Cell Metab 2012;16: 153-66.

42. Ebner N, Elsner S, Springer J, von Haehling $\mathrm{S}$. Molecular mechanisms and treatment targets of muscle wasting and cachexia in heart failure: an overview. Curr Opin Support Palliat Care 2014;8: 15-24.

43. Cohen S, Nathan JA, Goldberg AL. Muscle wasting in disease: molecular mechanisms and promising therapies. Nat Rev Drug Discov 2015;14: 58-74.

44. Cunha TF, Bacurau AV, Moreira JB, Paixão NA, Campos JC, Ferreira JC, et al. Exercise training prevents oxidative stress and ubiquitin-proteasome system overactivity and reverse skeletal muscle atrophy in heart failure. PLOS One 2012;7: e41701.

45. Jannig PR, Moreira JB, Bechara LR, Bozi $\mathrm{LH}$, Bacurau AV, Monteiro AW, et al. Autophagy signaling in skeletal muscle of infarcted rats. PLoS One 2014;9: e85820.

46. Ebner N, Steinbeck L, Doehner W, Anker $\mathrm{SD}$, von Haehling $\mathrm{S}$. Highlights from the 7th Cachexia Conference: muscle wasting pathophysiological detection and novel treatment strategies. J Cachexia Sarcopenia Muscle 2014;5: 27-34.

47. Attaix $D$, Combaret $L$, Béchet $D$, Taillandier D. Role of the ubiquitinproteasome pathway in muscle atrophy in cachexia. Curr Opin Support Palliat Care 2008:2: 262-6.

48. Moylan JS, Reid MB. Oxidative stress, chronic disease, and muscle wasting. Muscle Nerve 2007;35: 411-29.

49. Tisdale MJ. The ubiquitin-proteasome pathway as a therapeutic target for muscle wasting. J Support Oncol 2005;3: 209-17.

50. Lee D, Goldberg AL. SIRT1 by blocking the activities of FoxO1 and 3 inhibits muscle atrophy and promotes muscle growth. $J$ Biol Chem 2013;288: 30515-26.

51. Du Bois P, Pablo Tortola C, Lodka D, Kny $\mathrm{M}$, Schmidt $\mathrm{F}$, Song $\mathrm{K}$, et al. Angiotensin II induces skeletal muscle atrophy by activating TFEB-mediated MuRF1 expression. Circ Res 2015;117: 424-36.

52. Alamdari N, Aversa Z, Castillero E, Hasselgren PO. Acetylation and deacetylation: novel factors in muscle wasting. Metabolism 2013;62: 1-11.

53. Elkina $Y$, von Haehling $S$, Anker SD, Springer J. The role of myostatin in muscle wasting: an overview. J Cachexia Sarcopenia Muscle 2014;2: 143-51.

54. Dschietzig TB. Myostatin-from the mighty mouse to cardiovascular disease and cachexia. Clin Chim Acta 2014;433: 216-24.

55. Ebner N, Springer J, Kalantar-Zadeh $\mathrm{K}$ Lainscak M, Doehner W, Anker SD, et al. Mechanism and novel therapeutic approaches to wasting in chronic disease. Maturitas 2013;75: 199-206.

56. Busquets $S$, Toledo $M$, Orpi M, Massa D, Porta M, Capdevila E, et al. Myostatin blockage using actRIIB antagonism in mice bearing the Lewis lung carcinoma results in the improvement of muscle wasting and physical performance. $J$ Cachexia Sarcopenia Muscle 2012;3: 37-43.

57. Gielen S, Sandri M, Kozarez I, Kratzsch J, Teupser D, Thiery J, et al. Exercise training attenuates MuRF-1 expression in the skeletal muscle of patients with chronic heart failure independent of age: the randomized Leipzig Exercise Intervention in Chronic Heart Failure and Aging catabolism study. Circulation 2012;125: 2716-27.

58. Sirabella D, De Angelis L, Berghella L. Sources for skeletal muscle repair: from satellite cells to reprogramming. J Cachexia Sarcopenia Muscle 2013;4: 125-36.

59. Yablonka-Reuveni Z, Day K. Skeletal muscle stem cells in the spotlight: the satellite cell. In Cohen IS, Gaudette GR, eds. Regenerating the heart. New York, New York: Springer; 2011. p173-200.

60. Martins T, Vitorino R, Amado F, Duarte JA Ferreira R. Biomarkers for cardiac cachexia: reality or utopia. Clin Chim Acta 2014:436: 323-8.

61. von Haehling S, Anker SD. Treatment of cachexia: an overview of recent developments. Int J Cardiol 2015;184: 736-42.

62. Loncar G, Omersa D, Cvetinovic N, Arandjelovic A, Lainscak M. Emerging biomarkers in heart failure and cardiac cachexia. Int J Mol Sci 2014;15: 23878-96.

63. Palus S, von Haehling S, Springer J. Muscle wasting: an overview of recent developments in basic research. I Cachexia Sarcopenia Muscle 2014;5: 193-8.

64. Heymsfield SB, Adamek M, Gonzalez MC Jia G, Thomas DM. Assessing skeletal muscle mass: historical overview and state of the art. J Cachexia Sarcopenia Muscle 2014;5: 9-18.

65. von Haehling S, Lainscak M, Springer J Anker SD. Cardiac cachexia: a systematic overview. Pharmacol Ther 2009;121: 227-52.

66. Vaz Pérez A, Doehner W, von Haehling $S$, Schmidt H, Zimmermann AV, Volk HD, et al. The relationship between tumor necrosis factor-a, brain natriuretic peptide and atrial natriuretic peptide in patients with chronic heart failure. Int J Cardiol 2010;141: 39-43.

67. Anker SD, Ponikowski PP, Clark AL, Leyva $\mathrm{F}$, Rauchhaus $\mathrm{M}, \mathrm{Kemp} \mathrm{M}$, et al. Cytokines and neurohormones relating to body composition alterations in the wasting syndrome of chronic heart failure. Eur Heart J 1999;20: 683-93.

68. McEntegart MB, Awede B, Petrie MC Sattar N, Dunn FG, MacFarlane NG, et al. Increase in serum adiponectin concentration in patients with heart failure and cachexia: relationship with leptin, other cytokines, and B-type natriuretic peptide. Eur Heart J 2007;28: 829-35.
69. Schulze PC, Kratzsch J. Leptin as a new diagnostic tool in chronic heart failure. Clin Chim Acta 2005;362: 1-11.

70. Schulze PC, Kratzsch J, Linke A, Schoene $\mathrm{N}$, Adams V, Gielen $\mathrm{S}$, et al. Elevated serum levels of leptin and soluble leptin receptor in patients with advanced chronic heart failure. Eur J Heart Fail 2003;5: 33-40.

71. Doehner W, Pflaum C, Rauchhaus $M$, Godsland IF, Egerer K, Cicoira M, et al. Leptin, insulin sensitivity and growth hormone binding protein in chronic heart failure with and without cardiac cachexia. Eur J Endocrinol 2001;145: 727-35.

72. Sukhanov S, Semprun-Prieto L, Yoshida T, Michael Tabony A, Higashi Y, Galvez S, et al. Angiotensin II, oxidative stress and skeletal muscle wasting. Am J Med Sci 2011;342: 143-7.

73. Yoshida T, Tabony AM, Galvez S, Mitch WE, Higashi $Y$, Sukhanov S, et al. Molecular mechanisms and signaling pathways of angiotensin II-induced muscle wasting. potential therapeutic targets for cardiac cachexia. Int J Biochem Cell Biol 2013;45: 2322-32.

74. Cichello SA, Weisinger RS, Schuijers J, Jois $M$. 1-Sarcosine-angiotensin II infusion effects on food intake, weight loss, energy expenditure, and skeletal muscle UCP3 gene expression in a rat model. J Cachexia Sarcopenia Muscle 2014;5: 239-46.

75. Sanders PM, Russell ST, Tisdale MJ. Angiotensin II directly induces muscle protein catabolism through the ubiquitinproteasome proteolytic pathway and may play a role in cancer cachexia. $\mathrm{Br} \mathrm{J}$ Cancer 2005;93: 425-34.

76. von Haehling S, Doehner W, Anker SD. Nutrition, metabolism, and the complex pathophysiology of cachexia in chronic heart failure. Cardiovasc Res 2007;73 298-309.

77. Sengenès $C$, Berlan $M$, De Glisezinski I, Lafontan M, Galitzky J. Natriuretic peptides: a new lipolytic pathway in human adipocytes. FASEB J 2000;14: 1345-51.

78. Christensen HM, Kistorp C, Schou M, Keller N, Zerahn B, Frystyk J, et al. Cross-talk between the heart and adipose tissue in cachectic heart failure patients with respect to alterations in body composition: a prospective study. Metabolism 2014:63: 141-9.

79. Anker SD, Chua TP, Ponikowski P, Harrington D, Swan JW, Kox WJ, et al. Hormonal changes and catabolic/anabolic imbalance in chronic heart failure and their importance for cardiac cachexia. Circulation 1997:96: 526-34.

80. Müller TD, Nogueiras R, Andermann ML, Andrews ZB, Anker SD, Argente J, et al. Ghrelin. Mol Metab 2015;4: 437-60

81. Akamizu T, Kangawa K. Ghrelin for cachexia. J Cachexia Sarcopenia Muscle 2010;1: 169-76.

82. Ueno $H$, Yamaguchi $H$, Kangawa $K$, Nakazato M. Ghrelin: a gastric peptide that regulates food intake and energy homeostasis. Regul Pept 2005;126: 11-9. 
83. Attanasio P, Anker SD, Doehner W, von Haehling S. Hormonal consequences and prognosis of chronic heart failure. Curr Opin Endocrinol Diabetes Obes 2011;18: 224-30.

84. Nagaya $\mathrm{N}$, Uematsu $\mathrm{M}$, Kojima $\mathrm{M}$, Date $\mathrm{Y}$, Nakazato M, Okumura $\mathrm{H}$, et al. Elevated circulating level of ghrelin in cachexia associated with chronic heart failure. $\mathrm{Circu}-$ lation 2001;104: 2034-8.

85. Drey M, Sieber CC, Bauer JM, Uter W, Dahinden P, Fariello RG, et al. C-terminal agrin fragment as a potential marker for sarcopenia caused by degeneration of the neuromuscular junction. Exp Gerontol 2013;48: 76-80.

86. Hettwer $S$, Dahinden $P$, Kucsera $S$, Farina $\mathrm{C}$, Ahmed S, Fariello R, et al. Elevated levels of a C-terminal agrin fragment identifies a new subset of sarcopenia patients. Exp Gerontol 2013;48: 69-75.

87. Fragala MS, Jajtner AR, Beyer KS, Townsend JR, Emerson NS, Scanlon TC, et al. Biomarkers of muscle quality: $\mathrm{N}$ terminal propeptide of type III procollagen and C-terminal agrin fragment responses to resistance exercise training in older adults. I Cachexia Sarcopenia Muscle 2014;5: 139-48.

88. Lerner L, Guillory B, Chen J, Winston W, Weiler S, Gyuris J, et al. Growth differentiating factor-15 (GDF-15) induces anorexia and cachexia in mice: a novel pathway for cachexia. I Cachexia Sarcopenia Muscle 2013;4: 295-343 abstract 2-02.

89. Nedergaard A, Sun $S$, Karsdal MA Henriksen K, Kjær M, Lou Y, et al. Type $\mathrm{VI}$ collagen turnover-related peptidesnovel serological biomarkers of muscle mass and anabolic response to loading in young men. $J$ Cachex Sarcopenia Muscle 2013;4: 267-75.

90. Zou Y, Zhang RZ, Sabatelli P, Chu ML, Bönnemann CG. Muscle interstitial fibroblasts are the main source of collagen $\mathrm{VI}$ synthesis in skeletal muscle: implications for congenital muscular dystrophy types Ullrich and Bethlem. J Neuropathol Exp Neurol 2008;67: 144-54.

91. Bhasin S, He EJ, Kawakub M, Schroeder ET, Yarasheski K, Opiteck GJ, et al. N-terminal propeptide of type III procollagen as a biomarker of anabolic response to recombinant human GH and testosterone. $J$ Clin Endocrinol Metab 2009;94: 4224-33.

92. Scott IC, Tomlinson W, Walding $A$ Isherwood B, Dougall IG. Large-scale isolation of human skeletal muscle satellite cells from post-mortem tissue and development of quantitative assays to evaluate modulators of myogenesis. I Cachexia Sarcopenia Muscle 2013;4: 157-69.

93. Patel SS, Molnar MZ, Tayek JA, Ix JH, Noori $\mathrm{N}$, Benner $\mathrm{D}$, et al. Serum creatinine as a marker of muscle mass in chronic kidney disease: results of a cross-sectional study and review of literature. I Cachexia Sarcopenia Muscle 2013;4: 19-29.

94. Anker MS, von Haehling S, Springer J, Banach $M$, Anker SD. Highlights of mechanistic and therapeutic cachexia and sarcopenia research 2010 to 2012 and their relevance for cardiology. Arch Med Sci 2013;9: 166-71.

95. Oterdoom LH, Gansevoort RT, Schouten JP, de Jong PE, Gans RO, Bakker SJ. Urinary creatinine excretion, an indirect measure of muscle mass, is an independent predictor of cardiovascular disease and mortality in the general population. Atherosclerosis 2009;207: 534-40.

96. Lee PS, Bhan I, Thadhani R. The potential role of plasma gelsolin in dialysis-related protein-energy wasting. Blood Purif 2010;29: 99-101.

97. Lee PS, Sampath K, Karumanchi SA, Tamez $\mathrm{H}$, Bhan I, Isakova $\mathrm{T}$, et al. Plasma gelsolin and circulating actin correlate with hemodialysis mortality. I Am Soc Nephrol 2009;20: 1140-8.

98. Molnar MZ, Czira ME, Rudas A, Ujszaszi $A$, Lindner A, Fornadi $K$, et al. Association of the malnutrition-inflammation score with clinical outcomes in kidney transplant recipients. Am J Kidney Dis 2011;58: 101-8.

99. Marzetti E, Calvani R, Cesari M, Buford TW, Lorenzi M, Behnke BJ, et al. Mitochondrial dysfunction and sarcopenia of aging: from signaling pathways to clinical trials. Int J Biochem Cell Biol 2013;45: 2288-301.

100. von Haehling S. The wasting continuum in heart failure: from sarcopenia to cachexia. Proc Nutr Soc 2015;12: 1-11.

101. Maggioni AP, Anker SD, Dahlström U, Filippatos G, Ponikowski P, Zannad F, et al. Are hospitalized or ambulatory patients with heart failure treated in accordance with European Society of Cardiology guidelines? Evidence from 12 440 patients of the ESC Heart Failure Long-Term Registry. Eur J Heart Fail 2013;15: 1173-84.

102. Anker SD, Negassa A, Coats AJS, Afzal R, Poole-Wilson PA, Cohn JN, et al. Prognostic importance of weight loss in chronic heart failure and the effect of treatment with angiotensin-converting-enzyme inhibitors: an observational study. Lancet 2003;361: 1077-83.

103. Chen SZ, Xiao JD. Rosiglitazone and imidapril alone or in combination alleviate muscle and adipose depletion in a murine cancer cachexia model. Tumour Biol 2014;35: 323-32.

104. Schanze N, Springer J. Evidence for an effect of ACE inhibitors on cancer cachexia. J Cachexia Sarcopenia Muscle 2012;3: 139.

105. Alves $C R$, da Cunha TF, da Paixão NA, Brum PC. Aerobic exercise training as therapy for cardiac and cancer cachexia. Life Sci 2015;125: 9-14.

106. Rhee CM, Kalantar-Zadeh K. Resistance exercise: an effective strategy to reverse muscle wasting in hemodialysis patients? J Cachexia Sarcopenia Muscle 2014;5: 177-80.

107. Kirkman DL, Mullins $P$, Junglee NA, Kumwenda $\mathrm{M}$, Jibani MM, Macdonald $\mathrm{JH}$. Anabolic exercise in haemodialysis patients: a randomised controlled pilot study. J Cachexia Sarcopenia Muscle 2014;5: 199-207.

108. Kim JC, Shapiro BB, Zhang M, Li Y, Porszasz J, Bross $\mathrm{R}$, et al. Daily physical activity and physical function in adult maintenance hemodialysis patients. I Cachexia Sarcopenia Muscle 2014;5: 209-20.

109. Grande AJ, Silva V, Maddocks M. Exercise for cancer cachexia in adults : executive summary of a Cochrane Collaboration systematic review. J Cachexia Sarcopenia Muscle 2015;6: 208-11.

110. Piepoli MF, Conraads V, Corrà U, Dickstein $\mathrm{K}$, Francis DP, Jaarsma $\mathrm{T}$, et al. Exercise training in heart failure: from theory to practice. A consensus document of the heart failure association and the european association for cardiovascular prevention and rehabilitation. Eur I Heart Fail 2011;13: 347-57.

111. Spruit MA, Singh SJ, Garvey C, ZuWallack $R$, Nici L, Rochester C, et al. ATS/ERS Task Force on PulmonaryRehabilitation. An official American Thoracic Society/ European Respiratory Society statement: key concepts and advances in pulmonary rehabilitation. Am J Respir Crit Care Med 2013;188: e13-64.

112. Morley JE, von Haehling S, Anker SD. Are we closer to having drugs to treat muscle wasting disease? J Cachexia Sarcopenia Muscle 2014;5: 83-7.

113. McMurray JJ, Adamopoulos S, Anker SD, Auricchio A, Böhm M, Dickstein K, et al. ESC guidelines for the diagnosis and treatment of acute and chronic heart failure 2012: The Task Force for the Diagnosis and Treatment of Acute and Chronic Heart Failure 2012 of the European Society of Cardiology. Developed in collaboration with the Heart Failure Association (HFA) of the ESC. Eur J Heart Fail 2012;14: 803-69.

114. Moreira JB, Bechara LR, Bozi LH, Jannig PR, Monteiro AW, Dourado PM, et al. High- versus moderate-intensity aerobic exercise training effects on skeletal muscleof infarcted rats. I Appl Physiol 2013;114: 1029-41.

115. Tieland $M$, van de Rest $O$, Dirks ML, van der Zwaluw N, Mensink M, van Loon L, et al. Protein supplementation improves physical performance in frail elderly people: a randomized, double-blind, placebo-controlled trial. J Am Med Dir Assoc 2012;13: 720-6.

116. Bauer J, Biolo G, Cederholm T, Cesari M, Cruz-Jentoft AJ, Morley JE, et al. Evidence-based recommendations for optimal dietary protein intake in older people: a position paper from the PROTAGE Study Group. J Am Med Dir Assoc 2013;14: 542-59.

117. Rozentryt $P$, von Haehling $S$, Lainscak $M$ Nowak JU, KalantarZadeh K, Polonski L, et al. The effects of a high-caloric protein rich oral nutritional supplement in patients with chronic heart failure and $\mathrm{ca}$ chexia on quality of life, body composition, and inflammation markers: a randomized, double-blind pilot study. $J$ Cachexia Sarcopenia Muscle 2010;1: 35-42. 
118. Fumagalli S, Fattirolli F, Guarducci L, Cellai $\mathrm{T}$, Baldasseroni S, Tarantini F, et al. Coenzyme Q10 terclatrate and creatine in chronic heart failure: a randomized, placebo-controlled, double-blind study. Clin Cardiol 2011;34: 211-7.

119. Dutt V, Gupta S, Dabur R, Injeti E, Mittal A. Skeletal muscle atrophy: potential therapeutic agents and their mechanisms of action. Pharmacol Res 2015;99: 86-100.

120. Wakabayashi H, Sakuma K. Rehabilitation nutrition for sarcopenia with disability: a combination of both rehabilitation and nutrition care management. J Cachexia Sarcopenia Muscle 2014;5: 269-77.

121. Pineda-Juarez JA, Sanchez-Ortiz NA, Castillo-Martínez L, Orea-Tejeda A, Cervantes-Gaytan R, Keirns-Davis C, et al. Changes in body composition in heart failure patients after a resistance exercise program and branched chain amino acid supplementation. Clin Nutr 2015. doi:10.1016/j.clnu.2015.02.004 [Epub ahead of print].

122. Steffen BT, Lees SJ, Booth FW. Anti-TNF treatment reduces rat skeletal muscle wasting in monocrotaline-induced cardiac cachexia. J Appl Physiol 2008;105: 19501958.

123. Stroud M. Thalidomide and cancer cachexia: old problem, new hope? Gut 2005;54: 447-8.

124. Davis M, Lasheen W, Walsh D, Mahmoud F, Bicanovsky L, Lagman R. A Phase II dose titration study of thalidomide for cancerassociated anorexia. J Pain Symptom Manage 2012;43: 78-86.

125. Semmler J, Gebert U, Eisenhut T, Moeller J, Schönharting MM, Alléra A, et al. Xanthine derivatives: comparison between suppression of tumour necrosis factoralpha production and inhibition of cAMP phosphodiesterase activity. Immunology 1993;78: 520-525.

126. Combaret L, Tilignac T, Claustre A, Voisin $\mathrm{L}$, Taillandier D, Obled C, et al. Torbafylline (HWA 448) inhibits enhanced skeletal muscle ubiquitinproteasome-dependent proteolysis in cancer and septic rats. Biochem J 2002;361: 185-92.

127. Chasen M, Hirschman SZ, Bhargava R. Phase II study of the novel peptidenucleic acid OHR118 in the management of cancer-related anorexia/cachexia. J Am Med Dir Assoc 2011;12: 62-67.

128. Wen HS, Li X, Cao YZ, Zhang CC, Yang F, Shi YM, et al. Clinical studies on the treatment of cancer cachexia with megestrol acetate plus thalidomide. Chemotherapy 2012;58: 461-467.

129. Greig CA, Johns N, Gray C, MacDonald A Stephens NA, Skipworth RJ, et al. Phase I/II trial of formoterol fumarate combined with megestrol acetate in cachectic patients with advanced malignancy. Support Care Cancer 2014;22: 1269-75.

130. Cuvelier GD, Baker TJ, Peddie EF, Casey LM, Lambert PJ, Distefano DS, et al. A randomized, double-blind, placebo controlled clinical trial of megestrol acetate as an appetite stimulant in children with weight loss due to cancer and/or cancer therapy. Pediatr Blood Cancer 2014;61: 672-9.

131. Argilés JM, Anguera A, Stemmler B. A new look at an old drug for the treatment of cancer cachexia: megestrol acetate. Clin Nutr 2013;32: 319-24.

132. McCarthy HD, Crowder RE, Dryden S, Williams G. Megestrol acetate stimulates food and water intake in the rat: effects on regional hypothalamic neuropeptide Y concentrations. Eur I Pharmacol 1994;265: 99-102.

133. Mantovani G, Macciò A, Massa E, Madeddu C. Managing cancer-related anorexia/cachexia. Drugs 2001;61: 499-514.

134. Costa AM, Spence KT, Plata-Salamán CR, ffrench-Mullen JM. Residual Ca2+ channe current modulation by megestrol acetate via a g-protein alpha s-subunit in rat hypothalamic neurones. J Physiol 1995;487: 291-303.

135. Srivastava MD, Srivastava BIS, Brouhard B. $\Delta 9$ tetrahydrocannabinol and cannabidiol alter cytokine production by human immune cells. Immunopharmacology 1998;40: 179-85.

136. Watzl B, Scuderi P, Watson R. Marijuana components stimulate human peripheral blood mononuclear cell secretion of interferon-gamma and suppress interleukin-1 alpha in vitro. Int $J$ Immunopharmacol 1991;13: 1091-7.

137. Lenk K, Palus S, Schur R, Datta R, Dong J, Culler MD, et al. Effect of ghrelin and its analogues, BIM-28131 and BIM-28125, on the expression of myostatin in a rat heart failure model. $J$ Cachexia Sarcopenia Muscle 2013;4: 63-69.

138. Nagaya N, Moriya J, Yasumura $Y$, Uematsu $M$, Ono $F$, Shimizu $W$, et al. Effects of ghrelin administration on left ventricular function, exercise capacity, and muscle wasting in patients with chronic heart failure. Circulation 2004;110: 3674-9.

139. Temel J, Bondarde $S$, Jain $M$, Yan $Y$, Duus $\mathrm{E}$, Allen $\mathrm{S}$, et al. Efficacy and safety results from a phase II study of anamorelin $\mathrm{HCl}$, a ghrelin receptor agonist, in NSCLC patients. I Cachexia Sarcopenia Muscle 2013;4: 295-343 [Abstract 5-01].

140. Abernethy A, Temel J, Currow D, Gleich L, Friend J. Anamorelin $\mathrm{HCl}$ for the treatment of anorexia-cachexia in lung cancer: study design and baseline characteristics of patients in the phase III clinical trial ROMANA 2 (HT-ANAM-302). I Cachexia Sarcopenia Muscle 2013;4: 295-343 [Abstract 5-02].

141. White HK, Petrie CD, Landschulz W, MacLean D, Taylor A, Lyles K, et al. Effects of an oral growth hormone secretagogue in older adults. J Clin Endocrinol Metab 2009;94: 1198-206.

142. Ebner N, Werner CG, Doehner W, Anker SD, von Haehling S. Recent developments in the treatment of cachexia: highlights from the 6th Cachexia Conference. I Cachexia Sarcopenia Muscle 2012;3: 45-50.

143. Dalton JT, Barnette KG, Bohl CE, Hancock $\mathrm{ML}$, Rodriguez $\mathrm{D}$, Dodson $\mathrm{SH}$, et al. The selective androgen receptor modulator
GTx-024 (enobosarm) improves lean body mass and physical function in healthy elderly men and postmenopausal women: results of a double-blind, placebo controlled phase II trial. J Cachexia Sarcopenia Muscle 2011;2: 153-61.

144. Morley JE, Anker SD, von Haehling S. Prevalence, incidence, and clinical impact of sarcopenia: facts, numbers, and epidemiology-update 2014. J Cachexia Sarcopenia Muscle 2014;5: 253-9.

145. Crawford J, Dalton JT, Hancock ML, Johnston MA, Steiner M. Enobosarm, A selective androgen receptor modulator (SARM), increases lean body mass (LBM) in advanced non-small cell lung cancer patients in two pivotal, international phase 3 trials. I Cachexia Sarcopenia Muscle 2014;5: 35-78 [Abstract 5-15].

146. Dobs AS, Boccia RV, Croot CC, Gabrail NY, Dalton JT, Hancock ML, et al. Effects of enobosarm on muscle wasting and physical function in patients with cancer: a double-blind, randomised controlled phase 2 trial. Lancet Oncol 2013;14: $335-45$.

147. Takagi K, Horie K, Fujita E, Tanokura A, Hosoda S, Watanabe $\mathrm{H}$, et al. Anabolic effect of a novel long-acting SARM in rat ORX model. J Cachexia Sarcopenia Muscle 2013;4: 295-343 abstract 4-07.

148. Blanqué $R$, Lepescheux $L$, Auberval $M$, Minet D, Merciris D, Cottereaux C, et al. Characterization of GLPG0492, a selective androgen receptor modulator, in a mouse model of hind limb immobilization. BMC Musculoskelet Disord 2014;15: 291.

149. Cozzoli A, Capogrosso RF, Sblendorio VT, Dinardo MM, Jagerschmidt C, Namour F, et al. GLPG0492, a novel selective androgen receptor modulator, improves muscle performance in the exercised-mdx mouse model of muscular dystrophy. Pharmacol Res 2013;72: 9-24.

150. Ryall JG, Lynch GS. The potential and the pitfalls of beta-adrenoceptor agonists for the management of skeletal muscle wasting. Pharmacol Ther 2008;120: 219-32.

151. Quanjun $Y$, Genjin $Y$, Lili W, Bin L, Jin L, Qi $Y$, et al. Serum metabolic profiles reveal the effect of formoterol on cachexia in tumor-bearing mice. Mol Biosyst 2013;9: 3015-25.

152. Pötsch MS, Tschirner A, Palus $S$, von Haehling S, Doehner W, Beadle J, et al. The anabolic catabolic transforming agent (ACTA) espindolol increases muscle mass and decreases fat mass in old rats. $J$ Cachexia Sarcopenia Muscle 2014;5: 149-58.

153. Stewart Coats AJ, Srinivasan V, Surendran J, Chiramana H, Vangipuram SR, Bhatt NN, et al. The ACT-ONE trial, a multicentre, randomised, double-blind, placebocontrolled, dose-finding study of the anabolic/catabolic transforming agent, MT-102 in subjects with cachexia related to stage III and IV non-small cell lung cancer and colorectal cancer: study design. J Cachexia Sarcopenia Muscle 2011;24: 201-7. 
154. Stewart Coats AJ, Fuang HG, Prabhash K, von Haeling S, Tilson J, Brown R, et al. Espindolol for the treatment and prevention of cachexia in patients with stage III/IV non-small cell lung cancer or colorectal cancer (ACT-ONE): randomised, double-blind, placebo-controlled, international multi-centre phase II study. J Cachexia Sarcopenia Muscle 2014;5: 35-78 [Abstract 5-19].

155. Toledo M, Springer J, Busquets $S$, Tschirner A, López-Soriano FJ, Anker SD, et al. Formoterol in the treatment of experimental cancer cachexia: effects on heart function. I Cachexia Sarcopenia Muscle 2014;5: 315-20.

156. Bauerlein R, Pangilinan J, Salzler $R$, Abrahams C, Li B, Gromada J, et al. Efficacy of REGN1033, a fully human antimyostatin antagonist antibody, in rodent muscle function. I Cachexia Sarcopenia Muscle 2013;4: 295-343 abstract 4-06.

157. Zhou X, Wang JL, Lu J, Song Y, Kwak KS, Jiao $Q$, et al. Reversal of cancer cachexia and muscle wasting by ActRIIB antagonism leads to prolonged survival. Cell 2010;142: 531-543.

158. Creaney L, Hamilton B. Growth factor delivery methods in the management of sports injuries: the state of play. $\mathrm{Br} J$ Sports Med 2008;42: 314-20.

159. Banach $M$, Rizzo $M$, Toth PP, Farnier $M$, Davidson $\mathrm{MH}$, Al-Rasadi K, et al. Statin intolerance -an attempt at a unified definition. Position paper from an International Lipid Expert Panel. Arch Med Sci 2015;11: 1-23.

160. Paulus $S$, von Haehling $S$, Flach VC, Tschirner A, Doehner W, Anker SD, et al. Simvastatin reduces wasting and improves cardiac function as well as outcome in experimental cancer cachexia. Int J Cardiol 2013;168: 3412-8.

161. Reichman SE, Andrews RD, MacLean DA, Sheather S. Statins and dietary and serum cholesterol are associated with increased lean mass following resistance training. Gerontol A Biol Sci Med Sci 2007;62: 1164-71.

162. Rinaldi F, Perlingeiro RC. Stem cells for skeletal muscle regeneration: therapeutic potential and roadblocks. Transl Res 2014;163: 409-17.

163. Khawaja T, Chokshi A, Ji R, Kato TS, Xu K, Zizola $C$, et al. Ventricular assist device implantation improves skeletal muscle function, oxidative capacity, and growth hormone/insulin-like growth factor-1 axis signaling in patients with advanced heart failure. J Cachexia Sarcopenia Muscle 2014;5: 297-305.

164. Kalantar-Zadeh K, Rhee C, Sim JJ, Stenvinkel P, Anker SD, Kovesdy CP. Why cachexia kills: examining the causality of poor outcomes in wasting conditions. $J$ Cachexia Sarcopenia Muscle 2013;4: 89-94.

165. Calvani R, Marini F, Cesari M, Tosato M, Anker SD, von Haehling S, et al. Biomarkers for physical frailty and sarcopenia: state of the science and future developments. J Cachexia Sarcopenia Muscle 2015 in press;doi:10.1002/jcsm.12051.
166. Nedergaard A, Karsdal MA, Sun $S$, Henriksen K. Serological muscle loss biomarkers: an overview of current concepts and future possibilities. I Cachexia Sarcopenia Muscle 2013;4: 1-17.

167. Hutchinson PJ, Jalloh I, Helmy A, Carpenter $\mathrm{KL}$, Rostami E, Bellander BM, et al. Consensus statement from the 2014 International Microdialysis Forum. Intensive Care Med 2015;41: 1517-28.

168. Trobec K, Kerec Kos M, von Haehling S, Springer J, Anker SD, Lainscak M. Pharmacokinetics of drugs in cachectic patients: a systematic review. PLoS One 2013;8: e79603.

169. Cvan Trobec K, Kerec Kos M, Trontelj J, Grabnar I, Tschirner A, Palus S, et al. Influence of cancer cachexia on drug liver metabolism and renal elimination in rats. J Cachexia Sarcopenia Muscle 2015;6: 45-52.

170. Fearon $\mathrm{KCH}$, Argiles JM, Baracos VE, Bernabei R, Coats AJS, Crawford J, et al. Request for regulatory guidance for cancer cachexia intervention trials. $J$ Cachexia Sarcopenia Muscle 2015;6:272-4.

171. Onesti JK, Guttridge DC. Inflammation based regulation of cancer cachexia. Biomed Res Int 2014;2014: 168407.

172. Pajak B, Orzechowska S, Pijet B, Pijet M, Pogorzelska A, Gajkowska B, et al. Crossroads of cytokine signaling-the chase to stop muscle cachexia. J Physiol Pharmacol 2008;59: 251-64.

173. Grounds MD, Radley HG, Gebski BL, Bogoyevitch MA, Shavlakadze T. Implications of cross-talk between tumour necrosis factor and insulin-like growth factor-1 signalling in skeletal muscle. Clin Exp Pharmacol Physiol 2008;35: 846-51.

174. Ghezzi P, Cerami A. Tumor necrosis factor as a pharmacological target. Methods $\mathrm{Mol}$ Med 2004;98: 1-8.

175. Fong $\mathrm{Y}$, Moldawer LL, Marano $\mathrm{M}$, Wei $\mathrm{H}$ Barber A, Manogue $\mathrm{K}$, et al. Cachectin/ TNF or IL-1 alpha induces cachexia with redistribution of body proteins. Am J Physiol 1989;256: R659-65.

176. White JP, Puppa MJ, Sato S, Gao S, Price $\mathrm{RL}$, Baynes JW, et al. IL- 6 regulation on skeletal muscle mitochondrial remodeling during cancer cachexia in the ApcMin/+ mouse. Skelet Muscle 2012;2: 14.

177. White JP, Puppa MJ, Gao S, Sato S, Welle $\mathrm{SL}$, Carson JA. Muscle mTORC1 suppression by IL-6 during cancer cachexia: a role for AMPK. Am J Physiol Endocrinol Metab 2013;304: E1042-52.

178. Boura P, Loukides S, Grapsa D, Achimastos A, Syrigos K. The diverse roles of adiponectin in non-small-cell lung cancer: current data and future perspectives. Future Oncol 2015;11: 2193-203.

179. Ntikoudi E, Kiagia M, Boura P, Syrigos KN. Hormones of adipose tissue and their biologic role in lung cancer. Cancer Treat Rev 2014;40: 22-30.

180. Mak RH, Cheung WW, Gertler A. Exploiting the therapeutic potential of leptin signaling in cachexia. Curr Opin Support Palliat Care 2014;8: 352-7.
181. Trobec K, Haehling S, Anker S, Lainscak M. Growth hormone, insulin-like growth factor 1 , and insulin signaling-a pharmacological target in body wasting and cachexia. J Cachexia Sarcopenia Muscle 2011;2: 191-200.

182. Doehner W, Rauchhaus M, Ponikowski $P$, Godsland IF, von Haehling S, Okonko DO, et al. Impaired insulin sensitivity as an independent risk factor for mortality in patients with stable chronic heart failure. $J$ Am Coll Cardiol 2005;46: 1019-26.

183. Wagner EF, Petruzzelli M. Cancer metabolism: a waste of insulin interference. Nature 2015;521: 430-1.

184. Honors MA, Kinzig KP. The role of insulin resistance in the development of muscle wasting during cancer cachexia. J Cachexia Sarcopenia Muscle 2012;3: 5-11.

185. Dev R. The assessment and management of cancer cachexia: hypogonadism and hypermetabolism among supportive and palliative care patients. Curr Opin Support Palliat Care 2014;8: 279-85.

186. Cicoira M, Kalra PR, Anker SD. Growth hormone: growth hormone resistance in chronic heart failure and its therapeutic implications. J Card Fail 2003;9: 219-26.

187. Delafontaine $P$, Brink $M$. The growth hormone and insulin-like growth factor 1 axis in heart failure. Ann Endocrinol (Paris) 2000;61: 22-6.

188. Svaninger G, Isaksson $\mathrm{O}$, Lundholm K. Growth hormone and experimental cancer cachexia. J Natl Cancer Inst 1987;79: 1359-65.

189. Bing C. Insight into the growth hormoneinsulin-like growth factor-I axis in cancer cachexia. Br J Nutr 2005;93: 761-3.

190. Fogelman DR, Holmes H, Mohammed K, Katz MH, Prado CM, Lieffers J, et al. Does IGFR1 inhibition result in increased muscle mass loss in patients undergoing treatment for pancreatic cancer? J Cachexia Sarcopenia Muscle 2014;5: 307-13.

191. Doehner W, Rauchhaus M, Florea VG Sharma R, Bolger AP, Davos $\mathrm{CH}$, et al. Uric acid in cachectic and noncachectic patients with chronic heart failure: relationship to leg vascular resistance. Am Heart J 2001;141: 792-9.

192. Springer J, Tschirner A, Hartman K, von Haehling S, Anker SD, Doehner W. The xanthine oxidase inhibitor oxypurinol reduces cancer cachexia-induced cardiomyopathy. Int J Cardiol 2013;168: 3527-31.

193. Agustsson T, Rydén $M$, Hoffstedt J, van Harmelen V, Dicker A, Laurencikiene J, et al. Mechanism of increased lipolysis in cancer cachexia. Cancer Res 2007;67: 5531-7.

194. Lafontan M, Moro C, Berlan M, Crampes F, Sengenes C, Galitzky J. Control of lipolysis by natriuretic peptides and cyclic GMP. Trends Endocrinol Metab 2008;19: 130-7.

195. Tzanis G, Dimopoulos S, Agapitou V, Nanas S. Exercise intolerance in chronic heart failure: the role of cortisol and the catabolic state. Curr Heart Fail Rep 2014:11: 70-9. 
196. Dev R, Hui D, Dalal S, Nooruddin Zl, Yennurajalingam S, Del Fabbro $\mathrm{E}$, et al. Association between serum cortisol and testosterone levels, opioid therapy, and symptom distress in patients with advanced cancer. J Pain Symptom Manage 2011;41: 788-95.

197. Müller TD, Perez-Tilve D, Tong J, Pfluger PT, Tschöp MH. Ghrelin and its potential in the treatment of eating/wasting disorders and cachexia. J Cachexia Sarcopenia Muscle 2010;1: 159-67.

198. Molfino A, Formiconi A, Rossi Fanelli F, Muscaritoli M. Ghrelin: from discovery to cancer cachexia therapy. Curr Opin Clin Nutr Metab Care 2014;17: 471-6.

199. Castillero E, Akashi H, Wang C, Najjar M, Ji $\mathrm{R}$, Kennel PJ, et al. Cardiac myostatin upregulation occurs immediately after myocardial ischemia and is involved in skeletal muscle activation of atrophy. Biochem Biophys Res Commun 2015;457: 106-11.

200. Heineke J, Auger-Messier M, Xu J, Sargent M, York A, Welle S, et al. Genetic deletion of myostatin from the heart prevents skeletal muscle atrophy in heart failure. Circulation 2010;121: 419-25.

201. George I, Bish LT, Kamalakkannan G, Petrilli CM, Oz MC, Naka $\mathrm{Y}$, et al. Myostatin activation in patients with advanced heart failure and after mechanical unloading. Eur J Heart Fail 2010;12: 444-53.

202. Gruson D, Ahn SA, Ketelslegers JM, Rousseau MF. Increased plasma myostatin in heart failure. Eur J Heart Fail 2011;13: 734-6.

203. Lenk K, Erbs $S$, Hollriege R, Beck E, Linke A, Gielen $S$, et al. Exercise training leads to a reduction of elevated myostatin levels in patients with chronic heart failure. Eur J Prev Cardiol 2012;19: 404-11.

204. Zamora E, Simo R, Lupon J, Galán A Urrutia A, González B, et al. Serum myostatin levels in chronic heart failure. Rev Esp Cardiol 2010;63: 992-6.

205. Loumaye $A$, de Barsy $M$, Nachit $M$, Lause $P$, Frateur $L$, van Maanen $A$, et al. Role of Activin $A$ and myostatin in human cancer cachexia. I Clin Endocrinol Metab 2015;100: 2030-8.

206. Lokireddy S, Wijesoma IW, Bonala S, Wei M, Sze SK, McFarlane C, et al. Myostatin is a novel tumoral factor that induces cancer cachexia. Biochem J 2012;446: 23-36.

207. Busquets $S$, Toledo $M$, Marmonti E, Orpi M, Capdevila E, Betancourt A, et al. Formoterol treatment down regulates the myostatin system in skeletal muscle of cachectic tumour-bearing rats. Oncol Lett 2012;3: 185-9.
208. Ma K, Mallidis C, Bhasin S, Mahabadi V, Artaza J, Gonzalez-Cadavid N, et al. Glucocorticoid-induced skeletal muscle atrophy is associated with upregulation of myostatin gene expression. Am J Physiol Endocrinol Metab 2003;285: E363-71.

209. Hayot M, Rodriguez J, Vernus B, Carnac G, Jean $\mathrm{E}$, Allen $\mathrm{D}$, et al. Myostatin upregulation is associated with the skeletal muscle response to hypoxic stimuli. $\mathrm{Mol}$ Cell Endocrinol 2011;332: 38-47.

210. Kalantar-Zadeh K, Streja E, Molnar MZ, Lukowsky LR, Krishnan M, Kovesdy CP, et al. Mortality prediction by surrogates of body composition: an examination of the obesity paradox in hemodialysis patients using composite ranking score analysis. Am J Epidemiol 2012;175: 793-803.

211. Molnar MZ, Streja E, Kovesdy CP, Bunnapradist S, Sampaio MS, Jing J, et al. Associations of body mass index and weight loss with mortality in transplant-waitlisted maintenance hemodialysis patients. $\mathrm{Am} J$ Transplant 2011;11: 725-36.

212. von Haehling S, Morley JE, Coats AJS, Anker SD. Ethical guidelines for publishing in the Journal of Cachexia, Sarcopenia and Muscle: update 2015. J Cachexia Sarcopenia Muscle 2015;6: 315-6. 